\title{
ANALISIS PENGARUH VARIABEL KUALITAS PELAYANAN \\ TERHADAP KEPUASAN PELANGGAN PADA KEDAI ICE \\ CREAM GUBUK BAMBU KAB. KEDIRI
}

\author{
Pandu Ardana H; Nurlaely; Eni Prastiti \\ Fakultas Ekonomi - Universitas Kadiri \\ E-mail : nurlaely@unik-kediri.ac.id
}

\begin{abstract}
The research objective to determine service quality regarding tangible, reliability, responsiveness, assurance, and empathy influences consumer satisfaction to analyze the most dominant factors affecting consumer satisfaction Kediri Regency Ice Cream Bamboo Hut. The population in this study was visitors at Kedai Ice Cream Gubuk Bambu, Kediri Regency. Sample 100 uses the Non-Probability Sampling technique with the Accidental sampling approach. Based on the results of multiple linear regression analysis conducted in this study, the regression equation is obtained as follows: $\mathrm{Y}=$ $0.155 X+0.205 X+0.123 X+0.191 X+0.368 X$. Analysis of indicator statistics is valid and the variables are reliable. Testing of classical assumptions, multicollinearity free regression models, heteroscedasticity does not occur, and is normally distributed. Individually each of the most influential variables emphaty variables with a regression coefficient of 0.368 , reliability regression coefficient of 0.205 , assurance regression coefficient 0.191 , tangible regression coefficient of 0.155 variable the lowest responsiveness regression coefficient of 0.123 .
\end{abstract}

Keywords: service quality, tangible, reliability, responsiveness, assurance, empathy, customer satisfaction

\begin{abstract}
ABSTRAK
Tujuan penelitian untuk mengetahui kualitas pelayanan mengenai tangible, reliability, responsiveness, assurance, dan emphatyapa berpengaruh terhadap kepuasan konsumen untuk menganalisis faktor paling dominan mempengaruhi kepuasan konsumen Kedai Ice Cream Gubuk Bambu Kabupaten Kediri. Populasi dalam penelitian ini pengunjung di Kedai Ice Cream Gubuk Bambu Kabupaten Kediri. Sampel 100 menggunakan teknik Non-Probability Sampling dengan pendekatan Accidental sampling. Berdasarkan pada hasil analisis regresi linier berganda yang telah dilakukan pada penelitian ini, didapat persamaan regresi sebagai berikut : $\mathrm{Y}=0,155 \mathrm{X}+0,205 \mathrm{X}+0,123 \mathrm{X}+0,191 \mathrm{X}+$ $0,368 \mathrm{X}$. Analisis data statistik indikator bersifat valid dan variabelnya bersifat reliabel. Pengujian asumsi klasik, model regresi bebas multikolinieritas, tidak terjadi heteroskedastisitas, dan berdistribusi normal.Secara individu masing-masing variabel yang paling berpengaruh variabel emphaty dengan koefisien regresi sebesar 0,368, reliability koefisien regresi sebesar 0,205, assurance koefisien regresi 0,191, tangible koefisien regresi 0,155 variable yang paling rendah responsiveness koefisien regresi 0,123
\end{abstract}

Kata kunci : kualitas layanan, tangible, reliability, responsiveness , assurance , emphaty, kepuasan konsumen 


\section{PENDAHULUAN}

Di era masuknya ke ruang lingkup dunia produk atau jasa yang bersaing di satu pasar lebih banyak dan beragam karena keterbukaan pasar. Pelayanan yang baik konsumen akan kembali lagi (Gandung Satriyono \& Desi Kristanti, 2018).Dengan pelayanan yang baik akan meningkatkan kepuasan konsumen (Yunanto, 2016). Potongan harga yang diberikan penjual kepada konsumen dengan tujuan untuk meningkatkan volume penjualan.

Dalam upaya membangun bisnis Kedai Ice Cream Gubuk Bambu akan menyediakan fasilitas yang mendukung hal-hal ini, memungkinkan konsumen untuk membeli. Pengelolaan dana tergantung pada keputusan pemerintah dengan melihat kondisi yang ada. Perusahaan harus punya strategi untuk membuat kualitas pelayanan yang dapat memberi kepuasan bagi konsumen (Putra, 2014).

Uraian di atas diajukan sebuah penelitian tentang hubungan kualitas layanan dan kepuasan pelanggan yang dijadikan penelitian judul Analisis Pengaruh Variabel Kualitas Pelayanan Terhadap Kepuasan Pelanggan Pada Kedai Ice Cream Gubuk Bambu Kab. Kediri.

\section{TINJAUAN PUSTAKA}

\section{KualitasPelayanan}

Dalam pasar global yang penuh persaingan, akan sulit bagi sebuah bisnis/usaha yang ada jika tidak memperhatikan kepuasan pelanggan. Perusahaan atau pelaku usaha yang gagal memuaskan pelanggan mereka akan memberikan pengalaman buruk (Kotler, 1997).

Studi ini membuat persepsi yang baik tentang kualitas layanan meningkatkan kepuasan pelanggan yang akan mempengaruhi profitabilitas perusahaan atau usaha (Boulding et al.1993). Menurut Beatty et al. (1996) penjual terhadap pembeli sering memiliki dampak positif pada perusahaan/usaha.

Kepusan adalah bagian dari perilaku pembelian daya konsumen. Konsumen yang ingin membeli produk dan mendapatkan layanan yang baik mereka akan setia. Konsumen yang loyal tidak puas akan menghentikan kesetiaannya.Hari (1998), menyatakan kepuasan dan bukan kepuasan adalah respon konsumen terhadap kenormalan dan dalam kinerja produk yang bercita-cita setelah penggunaannya.

Kualitas layanan adalah pemenuhan harapan atau konsumen telah menerima layanan yang berkualitas atau tidak. Kualitas jasa adalah keunggulan yang diinginkan 
untuk mengendalikan atas keinginan pelanggan untuk memenuhi apa yang di inginkan dapat diperoleh. Jika jasa yang didapat sesuai yang di inginkan maka kualitas jasa diprediksi baik dapat puas.

\section{Kepuasan Pelanggan}

Pendapat Kotler, kepuasan yaitu perasaan seseorang yang hasilnya dirasa sesuai dengan harapan (Kotler dkk, 2000:52). Tidak puas jika hasil tak sesuai harapan dan keinginan pelanggan (Tjiptono, 2004:349).

Kepuasan pelanggan merupakan respons pelanggan terhadap kinerja yang sesuai dengan apa yang dirasa pelanggan pada saat dia puas.(Rangkuti, 2002:30). Kotler berpendapat (2000:41), yang di gunakan untuk mengukur pelanggan, yaitu:Sistem keluhan dan saran,Survei kepuasan pelanggan,Ghost Shopping, Analisa pelanggan yang hilang

Kepuasan pelanggan memberikan masukan kepada perusahaan untuk jadi erat terciptanya loyalitas pelanggan untuk rekomendasi dariteman satu ke teman yang lainya untuk menguntungkan perusahaan baik dimata pelanggan maupun masyarakat, dan mendapat laba sebanyak banyaknya.

\section{Kerangka Berpikir}

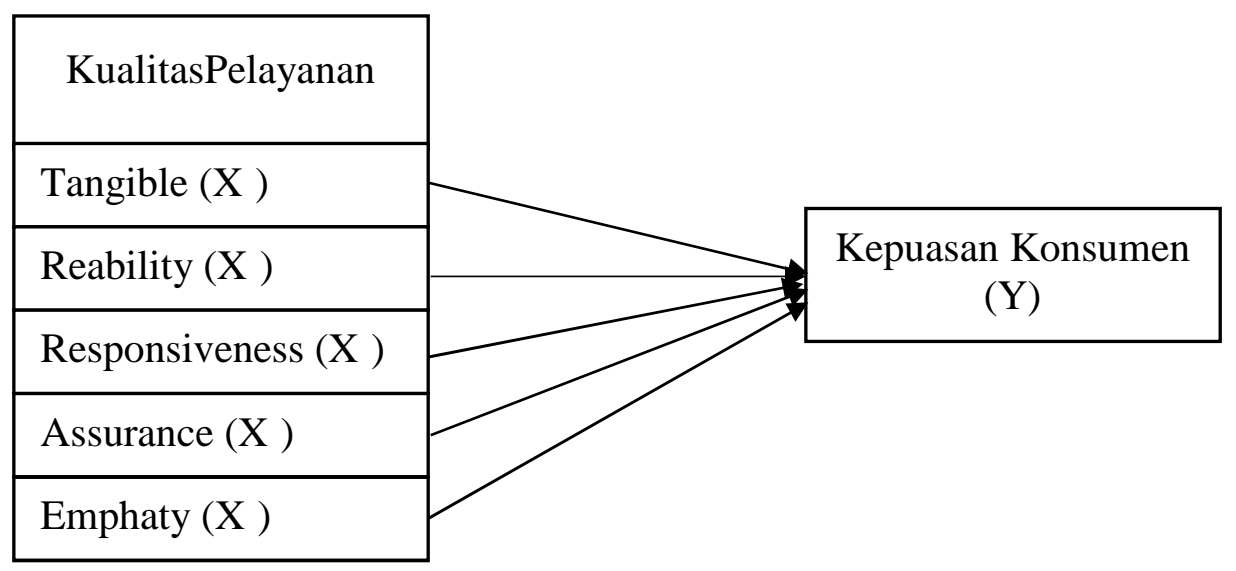

\section{Hipotesis}

H1 : tangible berpengaruh positif terhadap kepuasan konsumen.

H2 : Kehandalan / reliability berpengaruh positif terhadap kepuasan konsumen.

$\mathrm{H} 3$ : responsiveness berpengaruh positif terhadap kepuasan konsumen.

H4 : Jaminan/Assurance berpengaruh positif terhadap kepuasan konsumen. 
H5 : Kepedulian/Emphaty berpengaruh positif terhadap kepuasan konsumen.

\section{METODE PENELITIAN}

\section{Populasi}

Populasi dari orang yang berada padaKedai Ice Cream Gubuk Bambu minimal 2 kali.

\section{Sampel}

Sampel penelitian populasi digunakan 100 responden.

\section{Metode Pengambilan Sampel}

Penyebaran kuesioner mendatangi orang yang sedang berkunjung di Kedai Ice

Cream Gubuk Bambu dan sudah pernah berkunjung diKedai Ice Cream Gubuk Bambu lebih dari 1 kali.Hasil kuesioner tersebut valid.

Variabel Penelitian, Cara Pengukuran dan Definisi Operasional

Variabel Penelitian

Penelitian memiliki dua variabel :

1) Variabel Independen

Kualitas Pelayanan $(\mathrm{X})$ Tangible $\left(\mathrm{X}_{1}\right)$ Reliability $\left(\mathrm{X}_{2}\right)$ Responsiveness ( $\left.\mathrm{X}_{3}\right)$ Assurance $\left(\mathrm{X}_{4}\right)$ Emphaty $\left(\mathrm{X}_{5}\right)$

2) Variabel Dependen

1.Kepuasan Konsumen (Y).

\section{Cara Pengukuran}

Dengan skala likert variabel diukur menjadi indikator variabel. Setelah itu indikator menjadi titik tolak untuk menyusun item instrumen yang dapat berupa pernyataan atau pertanyaan.Sangat Setuju (SS) skor 5,Setuju (S)skor 4,Biasa (B)skor3, Tidak Setuju (TS) skor2, Sangat Tidak Setuju (STS) skor1.

\section{Definisi Operasional}

Tangible $\left(\mathrm{X}_{1}\right)$, Indikatornya : Bangunan dan interior yang bagus dan menarik, Kebersihan dan kenyamanan, Kelengkapan fasilitas yang ditawarkan, Kebersihan dan kerapian karyawan.Reliability $\left(\mathrm{X}_{2}\right)$, indikatornya : Hidangan yang disajikan sesuai dengan pesanan konsumen, Karyawan cepat dalam melayani konsumen, Pelayanan yang memuaskan. Responsiveness $\left(\mathrm{X}_{3}\right)$, indikatornya : Tanggap terhadap keluhan konsumen, Kesediaan karyawan membantu konsumen, Kecepatan dalam menyelesaikan masalah. Assurance $\left(\mathrm{X}_{4}\right)$, indikatornya : Keramahan dalam melayani konsumen, 
Pengetahuan karyawan mengenai menu yang disajikan, Keamanan konsumen terjamin. $\operatorname{Emphaty}\left(\mathrm{X}_{5}\right)$, indikatornya : Ketersedian layanan selama berkunjung, Mengetahui keinginan konsumen, Mampu berkomunikasi dengan baik. Kepuasan Konsumen (Y), indikatornya : Kenyamanan yang dirasakan pelanggan pada saat pelayanan diberikan, Keyakinan pelanggan atas pelayanan yang diberikan, Minat untuk selalu membeli produk yang disediakan, Perasaan puas atas perhatian dan pelayanan yang diberikan oleh karyawan.

Metode Pengumpulan Data :Data Primer,Data Sekunder

Teknik Pengumpulan Data :Kuesioner,Observasi,Studi Pustaka

Metode Analisis Data

Uji Validitas dan Reliabilitas

Uji Validitas

$$
\mathrm{rxy}=\frac{n \sum x y-\left(\Sigma x^{2}\right)\left(\sum y^{2}\right)}{\left.\sqrt{\left(n \sum x^{2}\right.}-(\Sigma x)\right\} \sqrt{\left\{\Sigma y^{2}-(\Sigma y)\right\}}}
$$

Dimana:

$$
\begin{aligned}
\operatorname{rxy} & =\text { koefisien korelasi (r-hitung) } \\
\mathrm{x} & =\text { Skor variabel independen } \\
\mathrm{y} & =\text { Skor variabel dependen } \\
\mathrm{xy} & =\text { Hasil kali skor butir dengan skor total } \\
\mathrm{n} & =\text { Jumlah responden }
\end{aligned}
$$

Uji Reliabilitas

$$
\alpha=\frac{k \cdot r}{1+(k-1) r}
$$

Dimana:

$\alpha=$ koefisien reliabilitas

$\mathrm{r}=$ korelasi antar item

$\mathrm{k}=$ jumlah item

Uji Asumsi Klasik

Uji Multikolinearitas

Nilai tolerance yang rendah sama dengan nilai VIF yang tinggi (karena $\mathrm{VIF}=1$ /tolerance ) dan menunjukkan adanya kolinearitas yang tinggi. Nilaicutoffyang 
umum dipakai adalah nilai tolerance 0,10 atau sama dengan nilai VIF dibawah 10 (Ghozali, 2005:92).

Uji Heteroskedastisitas

Jika titik-titik menyebar di atas dan di bawah angka 0 pada sumbu $\mathrm{Y}$ tanpa membentuk pola tidak terjadi heteroskedastisitas (Ghozali, 2005:105).

Uji Normalitas

Jika data menyebar disekitar garis diagonal dan mengikuti arah garis diagonal, maka model regresi memenuhi normalitas. Jika data menyebar jauh dari garis diagonal dan tidak mengikuti arah garis diagonal, maka model regresi tidak memenuhi normalitas. Analisis regresi Linier Berganda

$$
\mathrm{Y}=\mathrm{b} \mathrm{X}+\mathrm{b} \mathrm{X}+\mathrm{b} \mathrm{X}+\mathrm{b} \mathrm{X}+\mathrm{b} \mathrm{X}+\mathrm{e}
$$

Dimana:

$$
\begin{aligned}
\mathrm{Y} & =\text { Kepuasan Konsumen } \\
\mathrm{b} & =\text { Koefisien regresi variabel X1 (tangible) } \\
\mathrm{b} & =\text { Koefisien regresi variabel X2 (reliability) } \\
\mathrm{b} & =\text { Koefisien regresi variabel X3 (responsiveness) } \\
\mathrm{b} & =\text { Koefisien regresi variabel X4 (assurance) } \\
\mathrm{b} & =\text { Koefisien regresi variabel X5 (empathy) } \\
\mathrm{X} & =\text { Bukti fisik (Tangible) } \\
\mathrm{X} & =\text { Kehandalan (Reliability) } \\
\mathrm{X} & =\text { Daya tanggap (Responsiveness) } \\
\mathrm{X} & =\text { Jaminan (Assurance) } \\
\mathrm{X} & =\text { Empati kepedulian (Empathy) } \\
\mathrm{e} & =\text { error/variabel pengganggu }
\end{aligned}
$$

\section{Uji Hipotesis}

Uji Signifikansi Pengaruh Parsial (Uji T)

Ho : Variabel-variabel bebas tidak memiliki pengaruh signifikan terhadap variabel terikat.

Ha : Variabel-variabel bebas memiliki pengaruh signifikan terhadap variabel terikat.

Uji Signifikansi Pengaruh Simultan (Uji F) 
Ho: Variabel-variabel bebas tak memiliki pengaruh yang signifikan secara bersama-sama terhadap variabel terikatnya.

Ha : Variabel-variabel bebas memiliki pengaruh signifikan secara sama terhadap variabel terikatnya.

\section{Koefisien Determinasi $\left(\mathbf{R}^{2}\right)$}

Koefisien determinasi $\left(\mathrm{R}^{2}\right)$ mengetahui tingkat ketepatan paling baik dalam analisa regresi dimana ditunjukan besarnya koefisien determinasi $\left(\mathrm{R}^{2}\right) 0$ (nol) dan I (satu). Koefsien determinasi $\left(\left(\mathrm{R}^{2}\right)\right.$ nol variabel independen sama sekali tidak berpengaruh terhadap variabel dependen. Apabila koefisien determinasi mendekati satu, dapat dikatakan variabel independen merpengaruhivariabel dependen, koefisiendeterminasi $\left(\mathrm{R}^{2}\right)$ digunakan mengetahui prosentase perubahan variabel tidak bebas (Y) yang disebabkan oleh variabel bebas (X).

\section{HASIL PENELITIAN}

Usaha Kedai Ice Cream Gubuk Bambu Kabupaten Kediri dulunya adalah suatu rumah yang dipunyai oleh bapak Muntasir seorang warga Brenggolo, Plosoklaten, Kediri. Sebelum memulai usaha Bapak Muntasir sebelumnya bekerja di bidang pertanian, seiring berjalannya waktu beliau memikirkan untuk merenovasi rumahnya dan membuka usaha kuliner yang memliki keunikan tersendiri untuk pengunjung berkunjung dan memiliki ciri khas dalam usahanya tersebut.

Pada Mei 2014 beliau memulai usahanya dengan membuka Kedai Ice Cream Gubuk Bambu karena sangat jarang orang lain untuk membuka usaha dengan nama kedai dan menggunakan menu ice cream. Awal dalam melakukan usahanya bapak Muntasir dibantu keluarganya, seiring bertambahnya omset beliau memutuskan untuk mempekerjakan karyawan dan dalam segi menu Kedai Ice Cream Gubuk Bambu memiliki kurang lebih 25 menu, dan sekarang mempunya 50 menu.Dalam melakukan promosi bapak Muntasir mendatangi sekolah-sekolah untuk memberikan voucher kepada siswa yang berprestasi, yang nantinya siswa yang berprestasi tersebut akan mengajak teman-temannya untuk berkunjung ke Kedai Ice Gubuk Bambu.

Pada 10 April 2018 saya mendatangi Kedai Ice Cream untuk menemui bapak Muntasir dan meminta izin melakukan penelitian dan disetujui oleh beliau, Setelah itu 
saya minta data-data dari beliau untuk melakukan penelitian. Usaha yang beralamatkan di Jalan raya Brenggolo no. 19 ini memiliki keunikan tersendiri dari segi sejarah dan lokasi untuk saya melakukan penelitian. Dan pada tanggal 24 April 2018 saya menyebar kuesioner pada konsumen Kedai Ice Cream Gubuk Bambu.

\section{Gambaran Umum Responden}

Jumlah responden 100 orang pengumpulan data 100 buah kuesioner. Penentuan sampel orang yang sudah pernah berkunjung ke Kedai Ice Cream Gubuk Bambu Kabupaten Kediri. Adapun gambaran responden penelitian di klasifikasikan berdasarkan jenis kelamin, usia,dan frekuensi kunjungan.

\section{Responden Menurut Jenis Kelamin}

Responden pria 52 orang $52 \%$,wanita 48 orang $48 \%$.

\section{Responden Menurut Umur}

100 responden yang merupakan pelanggan Kedai Ice Cream Gubuk Bambu Kabupaten Kediri, maka diperoleh karakteristik responden berdasarkan umur.sumber data primer yang diolah peneliti (2018)

Umur responden usia 12 - 18 tahun 29 orang 29\%, usia 19 - 30 tahun 56 orang $56 \%$, usia 31-50 tahun 15 orang 15\%.total jumlah responden 100 presentase $100 \%$

Responden Menurut Frekuensi Kunjungan

Sumber : Data primer yang diolah peneliti, (2018) Frekuensi kunjungan 1- 2 kali 40 responden $40 \%, 3$ - 4 kali 28 responden $28 \%$, lebih dari 4 kali 32 responden 32 $\%$. total jumlah responden 100 presentase $100 \%$

\section{Hasil Penelitian}

Analisis Indeks Tanggapan Responden

Analisis dilakukan untuk mendapatkan gambaran deskriptif mengenai responden penelitian khususnya variabel penelitian yang digunakan kuesioner dengan menggunakan skala Likert

Nilai Indeks $=((\mathrm{F} 1 \times 1)+(\mathrm{F} 2 \times 2)+(\mathrm{F} 3 \times 3)+(\mathrm{F} 4 \times 4)+(\mathrm{F} 5 \times 5) / 5$

Dimana :

F1 frekuensi responden 1. 
F2 frekuensi responden 2.

F3frekuensi responden3.

F5 menjawab 5 skor yang digunakan kuesioner penelitian. angka responden dimulai dari angka 1 hingga 5. angka indeks yang dihasilkan 20 hingga 100 dengan rentang 80. penelitian menggunakan kriteria 3 kotak (three box method), rentang 80 dibagi 3menghasilkan rentang 26,67. Rentang ini akan digunakan untuk menentukan indeks persepsi konsumen terhadap variabel yang digunakan (Ferdinand, 2006:292), yaitu sebagai berikut :73,36 - 100,00 = Tinggi ,46,68 $73,35=$ Sedang, $20,00-46,67=$ Rendah

Indeks Tanggapan Responden Mengenai Bukti Fisik(Tangible)

\begin{tabular}{|c|l|c|c|c|c|c|c|c|c|}
\hline \multirow{2}{*}{ No } & \multicolumn{1}{|c|}{ Indikator } & \multicolumn{2}{|c|}{ Skor } & Jumlah & Indeks & Kriteria \\
\cline { 2 - 10 } 1 & $\begin{array}{l}\text { SS } \\
\text { Bangunan dan } \\
\begin{array}{l}\text { interior yang bagus } \\
\text { dan menarik }\end{array}\end{array}$ & 16 & 61 & 23 & 0 & 0 & 393 & 78,6 & Tinggi \\
\hline 2 & $\begin{array}{l}\text { Kebersihan dan } \\
\text { kenyamanan }\end{array}$ & 23 & 67 & 10 & 0 & 0 & 413 & 82,6 & Tinggi \\
\hline & $\begin{array}{l}\text { Kelengkapan } \\
\text { fasilitas yang } \\
\text { ditawarkan }\end{array}$ & 23 & 52 & 21 & 4 & 0 & 394 & 78,8 & Tinggi \\
\hline 4 & $\begin{array}{l}\text { Kebersihan dan } \\
\text { kerapian karyawan }\end{array}$ & 20 & 48 & 32 & 0 & 0 & 388 & 77,6 & Tinggi \\
\hline
\end{tabular}

Sumber : Data primer yang diolahpeneliti, (2018)

Perhitungan indeks tanggapan reponden mengenai bukti fisik adalah sebagai berikut :

1. Indikator 1, Nilai Indeks $=[(0 \times 1)+(0 \times 2)+(23 \times 3)+(61 \times 4)+(16 \times 5) /$ $5=78,60$

2. Indikator 2 ,Nilai Indeks $=[(0 \times 1)+(0 \times 2)+(10 \times 3)+(67 \times 4)+(23 \times 5) /$ $5=82,60$

3. Indikator 3,Nilai Indeks $=[(0 \times 1)+(4 \times 2)+(21 \times 3)+(52 \times 4)+(23 \times 5)] /$ $5=78,80$

4. Indikator 4,Nilai Indeks $=[(0 \times 1)+(0 \times 2)+(32 \times 3)+(48 \times 4)+(20 \times 5] /$ $5=78,80$ 
5. Bukti fisik $(\mathrm{X})$,Nilai Indeks $=(78,60+82,60+78,80+77,60) / 4=$ 79,40

Tanggapan respoden memberikan tanggapan penilaian setuju tinggi terhadap bukti fisik (tangible) nilai indeks 79,40.

Indeks Tanggapan Responden Mengenai Kehandalan (Reliability)

\begin{tabular}{|c|c|c|c|c|c|c|c|c|c|}
\hline \multirow{2}{*}{ No } & \multirow{2}{*}{ Indikator } & \multicolumn{5}{|c|}{ Skor } & \multirow{2}{*}{ Jumlah } & \multirow{2}{*}{ Indeks } & \multirow{2}{*}{ Kriteria } \\
\hline & & SS & $S$ & $\mathrm{~B}$ & TS & STS & & & \\
\hline 1 & $\begin{array}{l}\text { Hidangan yang disajikan } \\
\text { sesuai dengan pemesanan }\end{array}$ & 50 & 42 & 7 & 0 & 0 & 439 & 87,80 & Tinggi \\
\hline 2 & $\begin{array}{l}\text { Karyawan cepat dalam } \\
\text { melayani konsumen }\end{array}$ & 15 & 44 & 38 & 3 & 0 & 371 & 74,20 & Tinggi \\
\hline 3 & $\begin{array}{l}\text { Kelengkapan fasilitas yang } \\
\text { ditawarkan }\end{array}$ & 25 & 48 & 27 & 0 & 0 & 398 & 76,80 & Tinggi \\
\hline & Jumlah & & & & & & 1.208 & & \\
\hline & Index X & & & & & & 402,66 & 79,60 & Tinggi \\
\hline
\end{tabular}

Sumber : Data primer yang diolahpeneliti, (2018)

Perhitungan indeks tanggapan reponden mengenai kehandalan adalah sebagai berikut :

1. Indikator 1, Nilai Indeks $=[(0 \times 1)+(0 \times 2)+(7 \times 3)+(42 \times 4)+(50 \times 5)] / 5=87,80$

2. Indikator 2, Nilai Indeks $=[(0 \times 1)+(3 \times 2)+(38 \times 3)+(44 \times 4)+(15 \times 5)] / 5=74,20$

3. Indikator 3,Nilai Indeks $=[(0 \times 1)+(0 \times 2)+(27 \times 3)+(48 \times 4)+(25 \times 5)] / 5=$ 76,80

4. Kehandalan $\left(\mathrm{X}_{2}\right)$,Nilai Indeks $=[(87,80+74,20+76,80)] / 3=79,60$

Menunjukkan besarnya responden memberikan tanggapan setuju terhadap aspek kehandalan atau reliability dari jasa pelayanan dengan nilai indeks yang tinggi sebesar 79,60.

Indeks Tanggapan Responden Mengenai Daya Tanggap (Responsiveness)

\begin{tabular}{|c|c|c|c|c|c|c|c|c|c|}
\hline \multirow{2}{*}{ No } & \multirow{2}{*}{ Indikator } & \multicolumn{5}{|c|}{ Skor } & \multirow{2}{*}{ Jumlah } & \multirow{2}{*}{ Indeks } & \multirow{2}{*}{ Kriteria } \\
\hline & & SS & $S$ & $\mathrm{~B}$ & TS & STS & & & \\
\hline 1 & $\begin{array}{l}\text { Tanggap terhadap keluhan } \\
\text { konsumen }\end{array}$ & 20 & 45 & 35 & 0 & 0 & 385 & 77,00 & Tinggi \\
\hline 2 & $\begin{array}{l}\text { Kesediaan karyawan } \\
\text { membantu konsumen }\end{array}$ & 15 & 56 & 29 & 0 & 0 & 386 & 77,20 & Tinggi \\
\hline 3 & $\begin{array}{l}\text { Kecepatan dalam } \\
\text { menyelesaikan masalah }\end{array}$ & 16 & 49 & 35 & 0 & 0 & 381 & 76,20 & Tinggi \\
\hline & Jumlah & & & & & & 1.152 & & \\
\hline & Index X & & & & & & 384,00 & 76,80 & Tinggi \\
\hline
\end{tabular}

Sumber : Data primer yang diolah peneliti, (2018) 
Perhitungan indeks tanggapan reponden mengenai daya tanggap adalah sebagai berikut :

1. Indikator 1 ,Nilai Indeks $=[(0 \times 1)+(0 \times 2)+(35 \times 3)+(45 \times 4)+(20 \times 5)] / 5=$ 77,00

2. Indikator 2 ,Nilai Indeks $=[(0 \times 1)+(0 \times 2)+(29 \times 3)+(56 \times 4)+(15 \times 5)] / 5=$ 77,20

3. Indikator 3 ,Nilai Indeks $=[(0 \times 1)+(0 \times 2)+(35 \times 3)+(49 \times 4)+(16 \times 5)] / 5=$ 76,20

4. Daya Tanggap $\left(X_{3}\right)$, Nilai Indeks $=[(77,00+77,20+76,20)] / 3=76,80$

Kedai Ice Cream Gubuk Bambu Kabupaten Kadiri nilai indeks yang tinggi sebesar 76,80.

Indeks Tanggapan Responden Mengenai Jaminan (Assurance)

\begin{tabular}{|c|l|c|c|c|c|c|c|c|c|}
\hline \multirow{2}{*}{ No } & \multicolumn{1}{|c|}{ Indikator } & \multicolumn{5}{|c|}{ Skor } & Jumlah & Indeks & Kriteria \\
\cline { 2 - 9 } & $\begin{array}{l}\text { Keramahan dalam } \\
\text { melayani } \\
\text { pelanggan }\end{array}$ & 39 & 46 & 15 & 0 & 0 & 424 & 84,80 & Tinggi \\
\hline 2 & $\begin{array}{l}\text { Pengetahuan } \\
\text { karyawan } \\
\text { mengenai menu } \\
\text { yang disajikan }\end{array}$ & 17 & 65 & 16 & 2 & 0 & 397 & 79,40 & Tinggi \\
\hline 3 & $\begin{array}{l}\text { Keamanan } \\
\text { konsumen atau } \\
\text { tamu terjamin }\end{array}$ & 24 & 51 & 26 & 1 & 0 & 404 & 80,80 & Tinggi \\
\hline
\end{tabular}

Sumber : Data primer yang diolahpeneliti, (2018)

Perhitungan indeks tanggapan reponden mengenai jaminan adalah sebagai berikut :

1. Indikator 1, Nilai Indeks $=[(0 \times 1)+(0 \times 2)+(15 \times 3)+(46 \times 4)+(39 \times 5)]$ $15=84,80$

2. Indikator 2,Nilai Indeks $=[(0 \times 1)+(2 \times 2)+(16 \times 3)+(65 \times 4)+(17 \times 5)]$ $15=79,40$ 
3. Indikator 3,Nilai Indeks $=[(0 \times 1)+(1 \times 2)+(26 \times 3)+(51 \times 4)+(24 \times 5)]$ $/ 5=80,80$

4. Jaminan $\left(X_{4}\right)$, Nilai Indeks $=[(84,80+79,40+80,80)] / 3=81,66$

Kedai Ice Cream Gubuk Bambu Kabupaten Kadiri nilai indeks sangat tinggi sebesar 81,66.

Indeks Tanggapan Responden Mengenai Kepedulian (Emphaty)

\begin{tabular}{|c|l|c|c|c|c|c|c|c|c|}
\hline \multirow{2}{*}{ No } & \multicolumn{1}{|c|}{ Indikator } & \multicolumn{5}{|c|}{ Skor } & \multirow{2}{*}{ Jumlah } & Indeks & Kriteria \\
\cline { 2 - 9 } 1 & $\begin{array}{l}\text { Ketersediaan } \\
\text { layanan selama } \\
\text { berkunjung }\end{array}$ & 17 & 54 & 29 & 0 & 0 & 388 & 77,60 & Tinggi \\
\hline 2 & $\begin{array}{l}\text { Mengetahui } \\
\text { keinginan } \\
\text { pelanggan }\end{array}$ & 21 & 45 & 30 & 4 & 0 & 383 & 76,60 & Tinggi \\
\hline $\begin{array}{l}\text { Mampu } \\
\text { Berkomunikasi } \\
\text { dengan baik }\end{array}$ & 25 & 42 & 31 & 2 & 0 & 390 & 78,00 & Tinggi \\
\hline
\end{tabular}

Sumber : Data primer yang diolah peneliti, (2018)

Perhitungan indeks tanggapan reponden mengenai kepedulian adalah sebagai berikut :

1. Indikator 1,Nilai Indeks $=[(0 \times 1)+(0 \times 2)+(29 \times 3)+(54 \times 4)+(17 \times 5)] / 5=$ 77,60

2. Indikator 2 ,Nilai Indeks $=[(0 \times 1)+(4 \times 2)+(30 \times 3)+(45 \times 4)+(21 \times 5)] / 5=$ 76,60

3. Indikator 3,Nilai Indeks $=[(0 \times 1)+(1 \times 2)+(26 \times 3)+(51 \times 4)+(24 \times 5)] / 5=$ 78,00

4. Kepedulian $\left(\mathrm{X}_{5}\right)$, Nilai Indeks $=[(77,60+76,60+78,00)] / 3=77,40$

Kedai Ice Cream Gubuk Bambu Kabupaten Kadiri dalam pelayanan yang diberikannya nilai indeks yang tinggi sebesar 77,40. 
Indeks Tanggapan Responden Mengenai Kepuasan

\begin{tabular}{|c|c|c|c|c|c|c|c|c|c|}
\hline \multirow{2}{*}{ No } & \multirow{2}{*}{ Indikator } & \multicolumn{5}{|c|}{ Skor } & \multirow[t]{2}{*}{ Jumlah } & \multirow[t]{2}{*}{ Indeks } & \multirow[t]{2}{*}{ Kriteria } \\
\hline & & $\mathrm{SS}$ & $\mathrm{S}$ & $\mathrm{B}$ & $\mathrm{TS}$ & STS & & & \\
\hline 1 & $\begin{array}{l}\text { Kenyamanan yang di rasakan } \\
\text { pelanggan pada saat pelayanan } \\
\text { diberikan }\end{array}$ & 33 & 50 & 17 & 0 & 0 & 422 & 84.40 & Tinggi \\
\hline 2 & $\begin{array}{l}\text { Keyakinan pelanggan atas } \\
\text { pelayanan yang diberikan }\end{array}$ & 29 & 54 & 17 & 0 & 0 & 412 & 82,40 & Tinggi \\
\hline 3 & $\begin{array}{l}\text { Minat untuk selalu membeli } \\
\text { produk yang disediakan }\end{array}$ & 29 & 48 & 23 & 0 & 0 & 406 & 81,20 & Tinggi \\
\hline 4 & $\begin{array}{l}\text { Perasaan puas atas perhatian dan } \\
\text { pelayanan yang diberikan oleh } \\
\text { karyawan }\end{array}$ & 37 & 41 & 22 & 0 & 0 & 415 & 83,00 & Tinggi \\
\hline & Jumlah & & & & & & 1.655 & & \\
\hline & Rata-rata & & & & & & 413,75 & 82,75 & Tinggi \\
\hline
\end{tabular}

Sumber : Data primer yang diolah peneliti, (2018)

Perhitungan indeks tanggapan reponden mengenai kepuasan adalah sebagai berikut :

1. Indikator 1 , Nilai Indeks $=[(0 \times 1)+(0 \times 2)+(17 \times 3)+(50 \times 4)+(33 \times 5)] / 5=$ 84,40

2. Indikator 2 , Nilai Indeks $=[(0 \times 1)+(0 \times 2)+(17 \times 3)+(54 \times 4)+(29 \times 5)] / 5=$ 82,40

3. Indikator 3 , Nilai Indeks $=[(0 \times 1)+(0 \times 2)+(23 \times 3)+(48 \times 4)+(29 \times 5)] / 5=$ 81,20

4. Indikator 4 , Nilai Indeks $=[(0 \times 1)+(0 \times 2)+(22 \times 3)+(41 \times 4)+(37 \times 5)] / 5=$ 83,00

5. Kepuasan (Y), Nilai Indeks $=(84,40+82,40+81,20+83,00) / 4=82,75$

Kedai Ice Cream Gubuk Bambu Kabupaten Kadiri, dengan nilai indeks yang tinggi sebesar 82,75 .

\section{Uji Validitas dan Reliabilitas}

Uji Validitas

Variabel Bukti Fisik $\left(\mathrm{X}_{1}\right)$ indikator Bangunan dan interior yang bagus dan menarik $\mathrm{r}$ Hitung 0.545 r Tabel 0.217 valid. indikator Kebersihan dan kenyamanan r Hitung 0.642 $\mathrm{r}$ Tabel 0.217 valid. Indikator Kelengkapan fasilitas yang ditawarkan r Hitung $0.511 \mathrm{r}$ Tabel 0.217 valid. indikator kebersihan dan karyawan r Hitung 0.629 r Tabel 0.217 valid. 
Variabel kehandalan $\left(\mathrm{X}_{2}\right)$ indikator Hidangan yang disajikan sesuai dengan pemesanan rHitung 0.489 r Tabel 0.217 valid.indikator Karyawan cepat dalam melayani konsumen r Hitung $0.661 \mathrm{r}$ Tabel 0.217 valid. Indikator Kelengkapan fasilitas yang ditawarkan r Hitung 0.695 r Tabel 0.217 valid.

Variabel Daya Tanggap $\left(\mathrm{X}_{3}\right)$ indikator Tanggap terhadap keluhan konsumen $\mathrm{r}$ Hitung $0.673 \mathrm{r}$ Tabel 0.217 valid. indikator kesedian karyawan membantu konsumen $\mathrm{r}$ Hitung $0.602 \mathrm{r}$ Tabel0.217 valid. indikator kecepatan dalam menelesaikan masalah $\mathrm{r}$ Hitung $0.629 \mathrm{r}$ Tabel 0.217 valid.

Variabel Jaminan $\left(\mathrm{X}_{4}\right)$ indikator pengetahuan dalam melayani pelanggan $\mathrm{r}$ Hitung 0.519 rTabel 0.217 valid. indikator pengetahuan karyawan mengenai menu yang disajikan $r$ Hitung $0.393 \mathrm{r}$ Tabel 0.217 valid. Indikator keamanan konsumen atau tamu terjamin $\mathrm{r}$ Hitung $0.570 \mathrm{r}$ Tabel 0.217 valid.

Variabel kepedulian $\left(\mathrm{X}_{5}\right)$ indikator ketersediaan layanan selama berkunjung $\mathrm{r}$ Hitung $0.648 \mathrm{r}$ Tabel 0.217 valid. Indikator mengetahui keinginan pelanggan r Hitung $0.625 \mathrm{r}$ Tabel 0.217 valid. indikator mampu berkomunikasi dengan baik r Hitung $0.605 \mathrm{r}$ Tabel 0.217 valid.

Variabel kepuasan ( Y ) indikator Kenyamanan yang di rasakan pelanggan pada saat pelayanan diberikan r Hitung 0.738 r Tabel 0.217 valid. indikator Keyakinan pelanggan atas pelayanan yang diberikan r Hitung 0.790 r Tabel 0.217 valid. indikator Minat untuk selalu membeli produk yang disediakan r Hitung 0.574 r Tabel 0.217 valid. indikator Perasaan puas atas perhatian dan pelayanan yang diberikan oleh karyawan $r$ Hitung0.700 r Tabel 0.217 valid.

Indikator untuk mengukur variabel nilai korelasi 0,217.

\section{Uji Reliabilitas}

Variabel Bukti fisik 0.803 reliabel, kehandalan 0.666 reliabel, daya tanggap 0.851 reliabel, jaminan 0.507 tidak reliabel. kepedulian 0.750 reliabel.kepuasan 0.809 reliabel. Hasil uji reliabilitas 0,600 hampir semua konsep pengukur masing-masing variabel dari kuesioner.

Uji Asumsi Klasik 
Jika masih terdapat asumsi klasik maka model regresi tersebut masih memiliki bias. Jika suatu model ada masalah asumsi klasik maka dilakukan langkah revisi model untuk penyembuhan menghilangkan suatu masalah .

Uji Multi kolinearitas

Variabel Bukti fisik 1.491 tidak multi kolonier, kehandalan 1.915 tidak multi kolonier, daya tanggap 1.526tidak multi kolonier, jaminan 1.500tidak multi kolonier. kepedulian 1.562. tidak multi kolonier. Hasil pengujian menunjukkan bahwa nilai VIF dari semua variabel bebas memiliki nilai yang lebih kecil dari 10 .

Uji Heteroskedastisitas

Bila titik-titik data penyebar berada di atas dan dibawah atau disekitar angka 0, titik-titik tidak mengumpul hanya di atas atau di bawah saja, penyebaran titik data tidak membentuk pola. Hal ini bias disimpulkan bahwa ciri-ciri terpenuhi, sehingga dapat dikatakan bahwa dalam model regresi tidak terjadi masalah Heteroskedastisitas.

Uji Normalitas

Hasil analisis regresi linier dengan grafik normal P-P Plot terhadap residual error model regresi diperoleh sudah menunjukkan adanya pola grafik yang normal, yaitu adanya sebaran titik yang berada tidak jauh dari garis diagonal.

Analisis Regresi Linier Berganda

Model persamaan regresi dari hasil bentuk persamaan regresi :

$$
Y=0,155 X+0,205 X+0,123 X+0,191 X+0,368 X
$$

Persamaan regresi sebagai berikut :

a. Koefisien regresi variabel bukti fisikmemiliki arah positif untuk berpengaruh kepuasan konsumen.

b. Koefisien regresi variabel keandaan memiliki arah positif untuk berpengaruh kepuasan konsumen.

c. Koefisien regresi variabel daya tanggap memiliki arah positif untuk berpengaruh kepuasan konsumen.

d. Koefisien regresi variabel jaminan memilik arah positif untuk berpengaruh kepuasan konsumen.

e. Koefisien regresi variabel kepedulian memiliki arah positif untuk berpengaruh kepuasan konsumen . 
Hasil koefisien regresi berganda telah dijelaskan akan dilakukan pengujian hipotesis secara parsial maupun simultan.

\section{Uji Hipotesis}

Uji Signifikansi Parsial (Uji T)

Variabel secara parsial dapat diperoleh dengan menggunakan uji t.

1. Variabel Bukti Fisik (tangible)

Nilai $\mathrm{t}$ variabel tampilan fisik (tangible) nilai $\mathrm{t}=2,055$ nilai signifikansi $0,043<0,05$.

2. Variabel Kehandalan (reliability)

Nilai t variabel kehandalan (reliability) nilai $t=2,397$ nilai signifikansi0,018<0,05.

3. Variabel Daya tanggap (responsiveness)

Nilai $\mathrm{t}=1,612$ nilai signifikansi sebesar $0,110>0,05$.

4. Variabel Jaminan (assurance)

Nilai $\mathrm{t}=2,526$ dengan nilai signifikansi sebesar $0,013<0,05$.

5. Variabel kepedulian (empathy)

Nilait $=4,756$ nilai signifikansi $0,000<0,05$.

Hasil perhitungan statistik menunjukkan nilai $\mathrm{F}$ hitung $=33,465$ dengan signifikansi sebesar $0,000<0,05$.

\section{Koefisien Determinasi $\left(\mathbf{R}^{2}\right)$}

Adjusted $R^{2}$ sebesar 0,621berarti 62,1\% kepuasan konsumen dipengaruhi bukti fisik, kehandalan, daya tanggap, jaminan dan kepedulian 37,9\%.

Pembahasan

Peneliti keterbatasan penenelitian hanya memfokuskan 5 dimensi kualitas pelayanan terdiritangible, reliability, responsiveness, assurance, dan emphaty. seluruh variabel independen mempengaruhi variabel dependen kepuasan konsumen sebesar $62,1 \%$. Dan sisanya sebesar 37,9\% dipengaruhi variabel lain.

Hasil penelitian ini dapat dilaksanakan oleh Safira Farizah Nasbir (2017), Ratih Hardiyati (2010), Christiana Afrianti (2014) yang mengatakan kualitas pelayanan memiliki pengaruh positif serta signifikan terhadap kepuasan. 
Kesimpulkan semakin baik pemahaman kualitas pelayanan maka tujuan kepuasan pelanggan akan semakin efektif. karena konsep pemahaman kualitas dapat dilihat pada kemauan pelanggan, pemahaman pelanggan untuk mengetahui apa yang dihadapi permasalahan pelanggan maka pelanggan akan merasa suka dengan layanan Kedai Ice Cream Gubuk .

\section{KESIMPULAN DAN SARAN}

Kesimpulan

Berdasarkan hasilanalisis regresi linier berganda dilakukan penelitian persamaan regresi : $Y=0,155 X+0,205 X+0,123 X+0,191 X+0,368 X$

Maka dapat ditarik kesimpulan sebagai berikut :

1. Hasil analisis variabel bukti fisik (X) memiliki koefisien regresi sebesar 0,155 terhadap kepuasan konsumen (Y) nilai t hitung sebesar 2,055 dengan tingkat signifikansi 0,043(<0.05).

2. Hasil analisis variabel kehandalan $\left(X_{2}\right)$ memiliki koefisien regresi sebesar 0,205 terhadap kepuasan konsumen (Y) nilai t hitung sebesar 2,397dengan tingkat signifikansi $0,018(<0.05)$.

3. Hasil analisis variabel daya tanggap (X ) memiliki koefisien regresi sebesar 0,123 (bertanda negatif) kepuasan konsumen (Y) nilai t hitung sebesar 1,612 dengan tingkat signifikansi $(0,110>) \quad 0.05$.

4. Hasil analisis variabel jaminan (X ) memiliki koefisien regresi sebesar 0,191 kepuasan konsumen (Y) nilai thitung sebesar 2,526 dengan tingkat signifikansi $0,013(<0.05)$.

5. Hasil analisis diperoleh bahwa variable kepedulian (X) memiliki koefisien regresi 0,368 kepuasan konsumen (Y) nilai $\mathrm{t}$ hitung 4,756 tingkat signifikansi $0,000(<0.05)$.

6. Nilai Adjusted $R$ square 0,621 . Hal ini berarti bahwa $62,1 \%$ kepuasan konsumen (Y) variabel bukti fisik $\left(\mathrm{X}_{1}\right)$, kehandalan $\left(\mathrm{X}_{2}\right)$, daya tanggap $\left(\mathrm{X}_{3}\right)$, jaminan $\left(\mathrm{X}_{4}\right)$, dan kepedulian $\left(\mathrm{X}_{5}\right)$. Sedangkan $37,9 \%$ yang tidak diteliti dalam penelitian

\section{Saran}


Kualitas pelayanan yang dikasihkan oleh Kedai Ice Cream Gubuk Bambu Kabupaten Kediri sebagai berikut :

1. Pihak Kedai Ice Cream Gubuk Bambu Kabupaten Kediri perlu memperhatikan variabel daya tanggap yang berpengaruh dominan terhadap kepuasan konsumen, yaitu:Tanggap terhadap keluhan konsumen,Kesediaan karyawan membantu konsumen,Kecepatan dalam menyelesaikan masalah

2. Dalam penelitian ini kepuasan konsumen dipengaruhi oleh faktor lain selain kualitas pelayanan sebesar 37,9\%, maka pihak Kedai Ice Cream Gubuk Bambu Kabupaten Kediri memilikifaktor lain tersebut dapat berupa faktor kinerja (performance), keistimewaan tambahan (features), daya tarik produk terhadap panca indera (estetika) dan promosi (promotion) yang dapat mempengaruhi kepuasan konsumen.

3. Sebagai referensi peneliti dan lebih memperluas variabel independen lain selain bukti fisik, kehandalan, daya tanggap, jaminan, dan kepedulian untuk mempengaruhi variabel dependen kepuasan konsumen misal mungkin bisa mempengaruhi kepuasan konsumen dan dapat memperluas lagi objek yang diteliti.

\section{DAFTAR PUSTAKA}

Afrianti, Christiana. 2014. Analisis Pengaruh Variabel Kualitas Pelayanan Terhadap Kepuasan Nasabah Pada PT. Pegadaian Cabang Kediri. Kediri: Penerbit Universitas Kadiri

Asep M.Ramdan. 2008 Oktober 22. Hubungan Kualitas Jasa dan kepuasan Konsumen. (http://asep-m-ramdan.blogspot.com).

Aviliani, R dan Wilfridus, L. 1997. Membangun Kepuasan Pelanggan Melalui Kualitas Pelayanan. Usahawan, No.5

Fandy Tjiptono. 1997. Strategi Pemasaran (Edisi II). Yogyakarta: Penerbit Andi.

Freddy Rangkuti. 2002. Measuring Customer Satisfaction (cetakan ketiga). Jakarta: PT.Gramedia Pustaka Utama.

Gandung Satriyono \& Desi Kristanti. (2018). Pengaruh kepuasan pasien pada kualitas layanan Rawat Inap terhadap niat Discharge Against Medical Advice ( DAMA ) ( Studi di Rumah Sakit Umum Daerah Pare Kabupaten Kediri ). Ekonika, 3(2), 136153. https://doi.org/https://doi.org/10.30737/ekonika.v3i2.190

Putra, Y. P. (2014). Formulasi Strategi Bersaing Pada Universitas Kadiri Dalam Menghadapi Persaingan Antar Perguruan Tinggi Sejenis di Kota Kediri. Universitas Airlangga, Surabaya.

Yunanto, Y. (2016). Analisis pengaruh kualitas pelayanan dan disiplin kerja karyawan terhadap kepuasan pasien askes di pt askes kediri. Ekonika, 1(1), 26-37. https://doi.org/http://dx.doi.org/10.30737/ekonika.v1i1.3 
Hardiyati, Ratih. 2010. Analisis Pengaruh Kualitas Pelayanan Terhadap Kepuasan Konsumen Menggunakan Jasa Penginapan (Villa) Argowisata Kebun Teh Pagilaran. Semarang: Penerbit Universitas Diponegoro

Imam Ghozali. 2005. Aplikasi Analisis Multivariate dengan Program SPSS. Semarang: Badan Penerbit Universitas Diponegoro.

Kotler, Philip dan A.B Susanto. 2000. Manajemen Pemasaran Jasa Di Indonesia, Analisis Perencanaan, Implementasi dan pengendalian (Edisi pertama). Jakarta: Salemba Empat.

Kotler, Philip. 2002. Manajemen Pemasaran (Edisi Milenium). Jakarta: PT Prenhalindo.

M. Nur Nasution. 2004. Manajemen Jasa Terpadu. Bogor: Ghalia Indonesia.

Nasbir, Safira Farizah. 2017. Pengaruh Kualitas Pelayanan Terhadap Kepuasan Pelanggan Salon Hair Nets. Kendari: Penerbit Universitas Halu Oleo

Rambat Lupiyoadi. 2004. Manajemen Pemasaran Jasa : Teori dan Pratek. Jakarta: PT salemba Empat.

S. Azwar. 1997. Metode Penelitian. Yogyakarta: Pustaka Pelajar.

Sugiyono. 2004. Metode Penelitian Bisnis. Bandung: CV. ALFABETA.

Sugiyono. 2007. Statistika Untuk Penelitian. Bandung: ALFABETA.

Sunarto. 2003. Perilaku Konsumen. Yogyakarta : AMUS Jogyakarta dan CV Ngeksigondo Utama.

Wisnalmawati. 2005. Pengaruh Persepsi Dimensi Kualitas Layanan Terhadap Niat pembelian Ulang. Jurnal Ekonomi dan Bisnis, No. 3 Jilid 10 2005, h. 153165. 